\title{
APLIKASI RFID UNTUK PEMBELAJARAN BAGI ANAK-ANAK MENGGUNAKAN PC
}

\author{
Romy Kautsar, Akuwan Saleh, Muh. Agus Zainudin \\ Mahasiswa Jurusan Teknik Telekomunikasi \\ Politeknik Elektronika Negeri Surabaya \\ Institut Teknologi Sepuluh Nopember, Kampus ITS, Surabaya 60111 \\ e-mail : Romxcool72@yahoo.com
}

\begin{abstract}
Abstrak
Pada tugas akhir ini, akan dikembangkan sebuah aplikasi RFID untuk pembelajaran bagi anak-anak menggunakan PC, RFID pada umumnya digunakan untuk mengidentifikasikan suatu benda, pada tugas akhir ini, RFID digunakan untuk menampilkan suatu pertanyaan dan menjawab suatu soal yang akan ditampilkan oleh PC, pada PC dibuat sebuah informasi tentang objek-objek yang terdapat didalamnya yang dapat disimpan dan diambil sebagai informasi.

Pada perancangannya sistem ini menggunakan RFID reader dan RFID tag sebagai inputan dari interaksi yang telah dilakukan oleh pengguna, sedangkan pada objeknya masing-masing akan diidentifikasi berdasarkan tag RFID, yang selanjutnya akan di lakukan proses mediasi ke dalam PC, dan akan menjadi sebuah aplikasi belajar bagi anak-anak. Oleh karena itu dilakukan penghubungan antara sistem RFID dan PC menggunakan kabel serial, sehingga data dari tag tersebut dapat diterima oleh program aplikasi pembelajaran, pada program aplikasi tersebut dibuat dengan menggunakan Ms. Visual Basic yang didalamnya terdapat komponen MSComm yang berfungsi untuk melewati data yang menggunakan serial port, sehingga sistem RFID dapat diterapkan sebagai metode pembelajaran bagi anak-anak.
\end{abstract}

Kata Kunci - PC, Pembelajaran, sistem RFID

\section{PENDAhUluAN}

Saat ini proses pembelajaran bagi anak-anak biasanya menggunakan objek yang tertulis dan dari gambar-gambar yang ada, hal ini sering membuat seorang anak menjadi jenuh dalam melakukan proses pembelajaran oleh karena itu penulis ingin melakukan penggunaan aplikasi komputer untuk sistem pembelajaran secara interaktif dan menarik.

Melihat fungsi yang amat besar dari penggunaan komputer maka penulis bermaksud untuk memadukan fungsi dari sebuah komputer dengan interaksi langsung dari seseorang menggunakan RFID system sehingga dapat dijadikan suatu aplikasi/inovasi yang bermanfaat bagi orang banyak. Radio Frequency Identification (RFID) adalah suatu metode penyimpan dan mengambil kembali data melalui gelombang radio dengan frekuensi tertentu menggunakan suatu peralatan yang disebut RFID tags atau transponders. RFID menggunakan chip yang dapat dideteksi pada range beberapa meter oleh pembaca RFID. Dengan memadukan aplikasi dari penggunaan komputer dengan RFID, sehingga proses belajar akan menjadi interaktif dan menarik, dengan mengakses RFID objek-objek tersebut akan muncul dan dapat dijadikan suatu media pengenalan objek, pengenalan warna, belajar berhitung serta belajar membaca.

\section{LANDASAN TEORI}

Bab ini terdiri dari teori-teori dasar yang berguna untuk melandasi pembuatan aplikasisistem pembelajaran menggunakan RFID. Teori-toeri tersebut diantaranya $R F I D$, komunikasi serial, pemrograman viual basic.

\subsection{RFID (Radio Frecuency Identification)}

RFID ( Radio Frekuensi IDentification) adalah proses identifikasi seseorang atau objek dengan menggunakan frekuensi transmisi sinyal radio. RFID menggunakan frekuensi radio untuk membaca informasi dari sebuah tag atau transponder (Transmitter + Responder). Tag RFID akan mengenali dirinya sendiri ketika mendeteksi sinyal $R F I D$ reader[1].

\subsubsection{Konfigurasi Umum}

RFID merupakan teknologi yang berfungsi untuk melakukan deteksi dan identifikasi terhadap suatu obyek melalui data yang ditransmisikan melalui frekuensi radio. Sistem tersebut minimal memerlukan sebuah tag (yang berfungsi sebagai transponder), sebuah reader (yang berfungsi sebagai interrogator), dan sebuah antenna (yang berfungsi sebagai coupling device). Reader biasanya terhubung dengan sebuah host computer atau perangkat lainnya yang memiliki kecerdasan untuk memproses lebih lanjut tag data dan memutuskan untuk mengambil suatu tindakan. Salah satu elemen penting pada RFID adalah data transfer. Data transfer terjadi ketika terjadi hubungan antara sebuah tag dengan sebuah reader, yang dikenal dengan coupling, melalui antenna baik yang terpasang pada tag tersebut maupun pada reader seperti yang diilustrasikan pada gambar berikut ini[7]. 


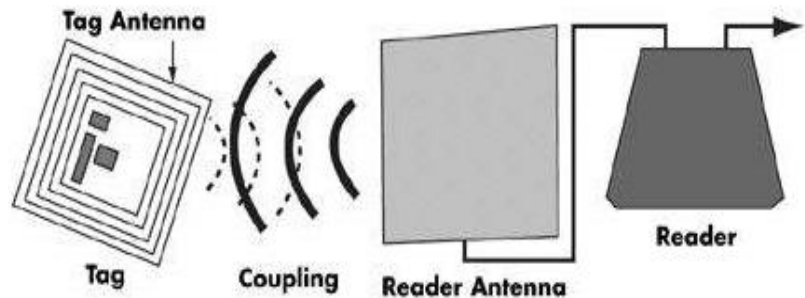

Gambar 2.1. Hubungan antara tag, reader, dan antenna

\subsubsection{Metode Coupling}

Coupling pada kebanyakan sistem-sistem RFID menggunakan metode magnetic (inductive) atau electromagnetic (backscatter). Metode yang digunakan tersebut bergantung pada harga, ukuran, kecepatan, dan jangkauan pembacaan serta keakuratan. Pada umumnya komunikasi antara sebuah tag dengan sebuah reader terjadi melalui sebuah physical principle yang dikenal sebagai sebuah backscatter modulation. Pada proses ini, sebuah reader mengirimkan sinyal kepada sebuah tag, dan tag akan menanggapinya dengan memantulkan sebagian dari energi ini kembali ke reader. Hal ini dapat diilustrasikan dari gambar 2.2[7].

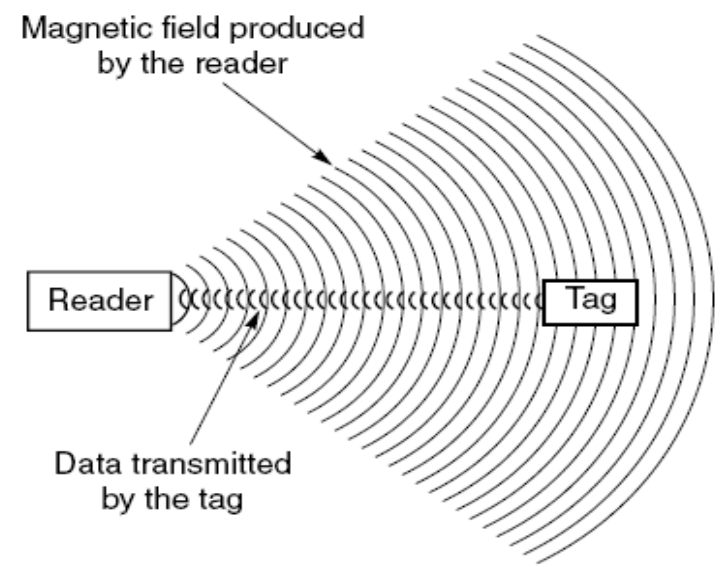

Gambar 2.2. Data transfer Pada RFID tag dan RFIDreader

\subsubsection{RFID reader}

RFID reader memiliki high frequency module (transmitter dan receiver), control module dan juga coupling element (coil dan microwave antenna), yang berfungsi membangkitkan sinyal untuk mengaktifkan RFID tags, sehingga dapat melakukan pengiriman dan penerimaan data. Ketika sebuah RFID tags melewati medan elektromagnetik RFID reader, maka RFID tags tersebut akan mendeteksi sinyal pengaktifan dari reader, dan mengirimkan sinyal balik untuk pemrosesan data yang telah tersimpan dalam memori tag sebagai respon. RFID reader kemudian menterjemahkan data yang dikirimkan oleh RFID tags tersebut sesuai dengan kebutuhan. Proses pembacaan kode-kode data yang terdapat pada RFID tags dilakukan menggunakan gelombang radio, sehingga proses pengidentifikasian menjadi lebih mudah,

\subsubsection{RFID tags (transponder)}

Pada sistem RFID umumnya, sebuah tag dipasangkan kepada suatu objek. Pada tag tersebut terdiri dari suatu integrated circuit dan sebuah coupling device, integrated circuit berfungsi menyimpan sebuah data khusus identifikasi dari suatu tag, sedangkan coupling device merupakan suatu interface dari RFID reader, RFID transponder coil merupakan suatu elemen dari coupling device yang berfungsi sebagai transmitting antenna, energi yang dimiliki pada RFID tags passive berasal dari RFID reader, energi tersebut digunakan untuk mengirimkan kembali data kepada reader, kapasitansi minimum dari pengisian kapasitor dapat dihitung menggunakan persamaan dibawah ini :

$C=\frac{Q}{U}=\frac{I t}{\left[V_{\max }-V_{\min }\right]}$

Vmax : Tegangan maksimum

Vmin : Tegangan minimum

I : Power consumption

$\mathrm{T}$ : Waktu yang diperlukan bagi transponder ke reader

Agar transponder dapat mengirimkan data identifikasi kepada reader, transponder perlu mendapat energi dari reader tersebut, untuk mengetahui besarnya energy yang diperlukan transponder untuk mengirimkan data ke reader dilakukanlah pencarian free space path loss sebagai berikut[3]:

$$
\begin{aligned}
& a_{\mathrm{F}}=-147.6+20 \log (r)+20 \log (f)-10 \log \left(G_{\mathrm{T}}\right)-10 \log \left(G_{\mathrm{R}}\right) . . \\
& \mathrm{r}=\text { Jarak transponder ke antena reader } \\
& \mathrm{Gr}=\text { Gain reader } \\
& \mathrm{Gt}=\text { Gain transponder } \\
& \mathrm{F} \quad=\text { Frekuensi operasi RFID }
\end{aligned}
$$

Berdasarkan catu daya tag, tag RFID dapat digolongkan menjadi tiga yang ditunjukkan pada gambar 2.3:

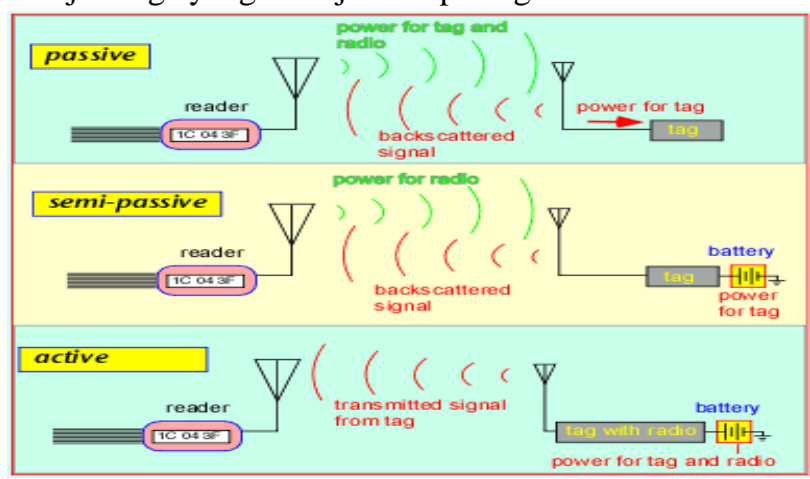

Gambar 2.3 Penggolongan RFID tag

- Tag Aktif: yaitu tag yang catu dayanya diperoleh dari batere, sehingga akan mengurangi daya yang diperlukan oleh pembaca RFID, dan tag dapat mengirimkan informasi dalam jarak yang lebih jauh. Kelemahan dari tipe tag ini adalah harganya yang mahal dan ukurannya yang lebih besar karena lebih komplek. Semakin banyak fungsi yang dapat dilakukan 
oleh tag RFID maka rangkaiannya akan semakin komplek dan ukurannya akan semakin besar.

- Tag Pasif: yaitu tag yang catu dayanya diperoleh dari medan yang dihasilkan oleh pembaca RFID. Rangkaiannya lebih sederhana, harganya jauh lebih murah, ukurannya kecil, dan lebih ringan. Kelemahannya adalah tag hanya dapat mengirimkan informasi dalam jarak yang dekat dan pembaca RFID harus menyediakan daya tambahan untuk tag RFID.

- Tag semi pasif adalah tag pasif yang menggunakan energi dari baterai untuk keperluan rangkaian, tetapi tidak untuk menghasilkan sinyal. Ketika baterai digunakan untuk memberikan energi pada sensor, maka ini disebut sensor tag. Tag ini cenderung lebih kecil dan lebih murah jika dibandingkan dengan tag aktif, juga memiliki fungsi lebih jika dibandingkan dengan tag pasif karena lebih banyak energi yang tersedia untuk kegunaan lain[6].

\subsubsection{Frekuensi Kerja RFID}

Berikut ini adalah frekuensi yang digunakan untuk komunikasi wireless antara pembaca RFID dengan tag RFID. Ada beberapa band frekuensi yang digunakan untuk sistem RFID. Frekuensi yang digunakan dalam sistem RFID dapat ditunjukan pada tabel 2.1 berikut:

Tabel 2.1 Frekuensi Kerja RFID

\begin{tabular}{|l|l|l|l|}
\hline Gelombang & Frekuensi & Rentang dan laju baca & Contoh penggunaan \\
\hline LF & $125 \mathrm{KHz}$ & $\begin{array}{l}\sim 1.5 \text { kaki; } \\
\text { kecepatan baca rendah }\end{array}$ & $\begin{array}{l}\text { Access control, animal } \\
\text { tracking, point of sale } \\
\text { applications }\end{array}$ \\
\hline HF & $13.56 \mathrm{MHz}$ & $\begin{array}{l}\sim 3 \text { kaki; } \\
\text { kecepatan baca } \\
\text { sedang }\end{array}$ & $\begin{array}{l}\text { Access control, smart } \\
\text { cards, item-level } \\
\text { tracking }\end{array}$ \\
\hline UHF & $860-930 \mathrm{MHz}$ & $\begin{array}{l}\text { up to 15 kaki; } \\
\text { kecepatan baca tinggi }\end{array}$ & $\begin{array}{l}\text { Pallet tracking, supply } \\
\text { chain management }\end{array}$ \\
\hline Gelombang mikro & $2.4515 .8 \mathrm{GHz}$ & $\begin{array}{l}-3 \text { kaki; } \\
\text { kKecepatan baca tinggi }\end{array}$ & $\begin{array}{l}\text { Supply chain } \\
\text { managaement }\end{array}$ \\
\hline
\end{tabular}

\subsection{Komunikasi Serial}

RS-232 menawarkan komunikasi asyncronus dengan kombinasi start dan stop bit yang digunakan untuk mensinkronkan masing-masing data frame. Parity bit digunakan oleh penerima untuk menentukan jika angka ganjil bit telah rusak pada saat transmisi. Pada gambar 2.6 ditunjukkan output data ASCII dari RFID reader yang dihasilkan dari pembacaan RFID tag menggunakan komunikasi serial[1].

\begin{tabular}{|l|l|l|l|l|l|}
\hline $\begin{array}{l}02 \\
(1 \text { byte })\end{array}$ & $\begin{array}{l}10 \text { ASCII Hex Data Characters } \\
\text { (10bytes) }\end{array}$ & $\begin{array}{l}2 \text { ASCII char's Checksum } \\
\text { (2byte) }\end{array}$ & $\begin{array}{l}\text { CR } \\
\text { (1byte) }\end{array}$ & $\begin{array}{l}\text { LF } \\
\text { (1byte) }\end{array}$ & $\begin{array}{l}03 \\
\text { (1byte) }\end{array}$ \\
\hline
\end{tabular}

Gambar 2.4 Format paket data Output RFID reader Panjang dari total paket adalah 16 bytes[4],

Contoh:

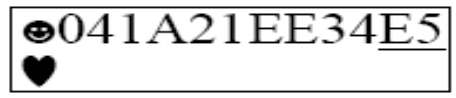

E $5=$ Checksum

() $=02 \mathrm{ASCII}$
$=03$ ASCII

checksum di dapat dari :

$04_{\text {hex }} \oplus 1 \mathrm{~A}_{\text {hex }} \oplus 21_{\text {hex }} \oplus \mathrm{E} E_{\text {hex }} \oplus 34_{\text {hex }}=\mathrm{E} 5_{\text {hex }}$

\subsection{Pemrograman Ms. Visual Basic 6.0}

Ms. Visual Basic digunakan sebagai perangkat lunak untuk pembuatan program dengan aplikasi GUI (Graphical User Interface), atau program yang memungkinkan pengguna komputer dapat berkomunikasi menggunakan media grafik atau gambar dengan komputer tersebut. Ms. Visual basic 6.0 menyediakan fasilitas yang memungkinkan untuk menyusun sebuah program dengan memasang objek-objek tertentu dalam sebuah form.

Pemrograman Ms. Visual Basic dapat di hubungkan dengan suatu perangkat keras yang berhubungan menggunakan serial port, contohnya adalah digunakan untuk aplikasi RFID, agar data RFID dapat diterima oleh program aplikasi digunakan suatu komponen dari $M s$. Visual Basic itu sendiri yaitu MSComm, komponen MSComm berfungsi untuk[5]:

1. Mengadakan hubungan dengan serial port $P C$

2. Berhubungan antara alat komunikasi lain (contohnya RFID)

3. Melakukan pertukaran data.

4. Memonitor dan merespon event dan error yang terjadi pada hubungan serial.

\section{PERENCANAAN SISTEM 3.1 ALAT DAN BAHAN}

Pada pembuatan suatu sistem perangkat lunak yang harus dipersiapkan terlebih dahulu adalah peralatan-peralatan serta program yang mendukung untuk pembuatan aplikasi ini, diantaranya adalah :

- RFID reader and tag : Berfungsi sebagai media komunikasi yang dijadikan suatu perintah dari pengguna aplikasi dengan aplikasi tersebut.

- PC (Personal computer) : Sebagai media untuk menjalankan aplikasi yang telah dibuat serta media untuk pembuatan aplikasi itu sendiri.

- Kabel serial DB9 : Berfungsi sebagai penghubung komunikasi antara sistem RFID dengan PC.

- Ms.Visual Basic : Berfungsi sebagai pembuatan program aplikasi.

- Swift 3d : Berfungsi untuk membuat objek-objek tiga dimensi yang akan dimainkan pada aplikasi

\subsection{CARA KERJA}

Prinsip kerja perangkat lunak adalah untuk melakukan proses pembelajaran untuk anak-anak menggunakan media RFID yang diantaranya adalah proses pengenalan objek-objek sederhana, belajar berhitung, menebak warna, dan membaca dengan menebak huruf yang kurang pada suatu kata.

\subsubsection{PERENCANAAN SISTEM UTAMA \\ Aplikasi pembelajaran bagi anak-anak menggunakan RFID meliputi sistem RFID yang}


diantaranya terdiri dari tag RFID dan RFID reader, tag RFID merupakan suatu transponder yang berisikan suatu data identitas yang dimodulasi dengan suatu frekuensi tertentu, RFID reader berfungsi sebagai alat yang mendeteksi dan menerima data dari RFID tag pada saat seseorang mengakses menggunakan RFID tag kepada RFID reader, sedangkan kabel serial RS232 berfungsi sebagai media transmisi pada proses pengiriman data dari RFID reader ke PC. Pada PC dibuatlah program aplikasi pembelajaran bagi anak-anak dengan menggunakan $M s$. Visual Basic yang menerima data dari tag RFID, data yang diterima tersebut dijadikan suatu perintah untuk menjalankan aplikasi pembelajaran diantaranya adalah pembelajaran pengenalan objek, berhitung, menebak warna, dan belajar membaca.

\subsubsection{PERENCANAAN PROGRAM APLIKASI}

Untuk melakukan perancangan program dibuatlah diagram alir atau flowchart hal ini bertujuan untuk menggambarkan suatu sistem program agar mudah dipahami dalam perancangan program. Diagram alir ini terdiri atas simbol untuk alternate procces yang menyatakan bahwa suatu program mulai atau berakhir, simbol kotak yang menyatakan procces, simbol decision yang menyatakan kondisi logika dan tanda panah yang menyatakan aliran program. Algoritma untuk cara kerja aplikasi pembelajaran untuk anak-anak menggunakan RFID secara umum seperti ditunjukkan gambar 3.1

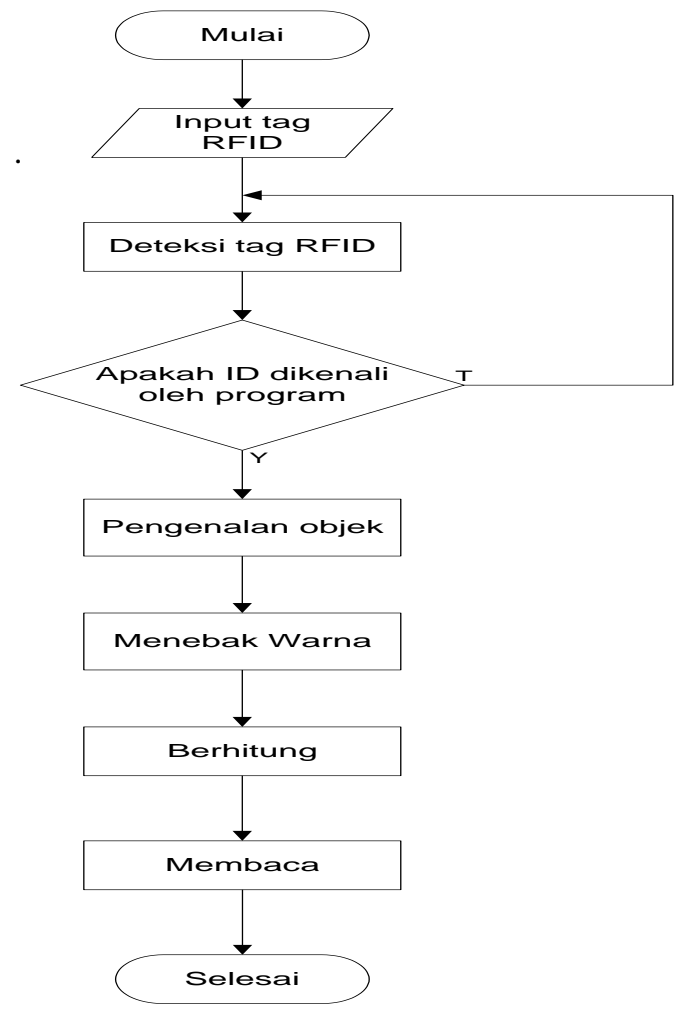

Gambar 3.1 Diagram alir sistem secara umum

\section{PEMBUATAN SISTEM, HASIL DAN PEMBAHASAN}

\subsection{PEMBUATAN SISTEM DAN IMPLEMENTASI}

Pembuatan aplikasi sistem pembelajaran menggunakan RFID ini diantaranya pembuatan form awal, form mengenal objek, form menebak warna, form berhitung, dan form belajar membaca serta menghubungkan RFID dengan PC, blok diagram dari sistem keseluruhan secara umum adalah sebagai berikut :

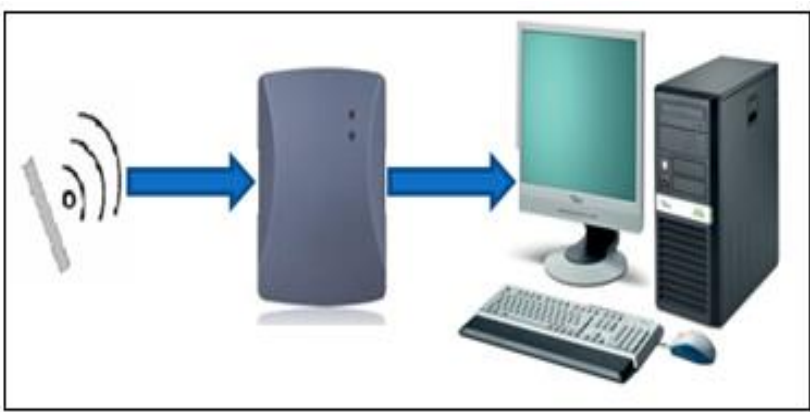

Gambar 4.1 Blok diagram aplikasi RFID untuk pembelajaran bagi anak-anak menggunakan RFID

\subsubsection{Koneksi antara RFID dengan PC}

Pada proses pengiriman dan penerimaan data dari reader RFID dan PC digunakan kabel serial DB 9, Hubungan antara komputer dengan RFID reader dapat dilihat pada konfigurasi sebagai berikut :

Tabel 4.1 Konfigurasi pin DB9 antara RFID reader dan PC

\begin{tabular}{|c|c|}
\hline $\begin{array}{c}\text { COM port } \\
\text { Komputer DB9 }\end{array}$ & RFID Starter Kit J1 \\
\hline RX (pin 2) & RX (pin 5) \\
\hline TX (pin 3) & TX (pin 4) \\
\hline GND (pin 5) & GND (pin 3) \\
\hline
\end{tabular}

\subsubsection{Pembuatan program aplikasi pembelajaran}

Pada pembuatan aplikasi pembelajaran untuk anak-anak menggunakan RFID, digunakan pemrograman menggunakan Ms. Visual Basic, pada umumnya setiap RFID tag hanya digunakan untuk mengidentifikasikan satu objek/benda, akan tetapi pada tugas akhir ini, setiap RFID tag mampu menampilkan bermacam-macam objek/benda dengan memanfaatkan pemrograman $M s$. Visual Basic, agar data dari RFID tag dapat diterima oleh pemrograman Ms. Visual Basic digunakan komponen MSComm pada Ms. Visual Basic.

Private Sub Form_Activate( $)$
ESComm1.PortOpen $=$ True
Private Sub Form_Deactivate( $)$
MSComm1.PortOpen = False
Unload Me
End Sub


Kode program diatas dan komponen MSComm yang tersedia pada Ms. Visual Basic digunakan pada setiap form pembelajaran yang dibuat, karena pada setiap form pembelajaran digunakan RFID untuk melakukan proses pembelajaran, kode program diatas juga menunjukkan penggunaan MSComm ketika form aktif, serial port dalam keadaan terbuka.

RFID tag yang digunakan pada aplikasi ini, sebanyak dua buah yang dikenali oleh program aplikasi pembelajaran, masing-masing RFID tag memiliki fungsi yang berbeda satu sama lain dalam menjalankan aplikasi pembelajaran, pada program aplikasi pembelajaran, dua RFID tag tersebut diberikan penamaan menjadi kartu A dan kartu B, secara umum fungsi dari kartu A dan B pada penggunaannya adalah:

- Kartu A berfungsi untuk menampilkan objek, dan soal pembelajaran.

- Kartu B berfungsi untuk menjawab pertanyaan/soal yang ditampilkan oleh kartu A dan mengakhiri program.

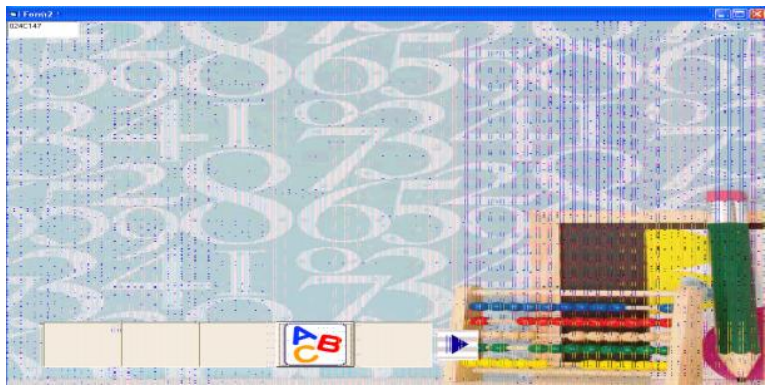

Gambar 4.2 Tampilan form menu awal

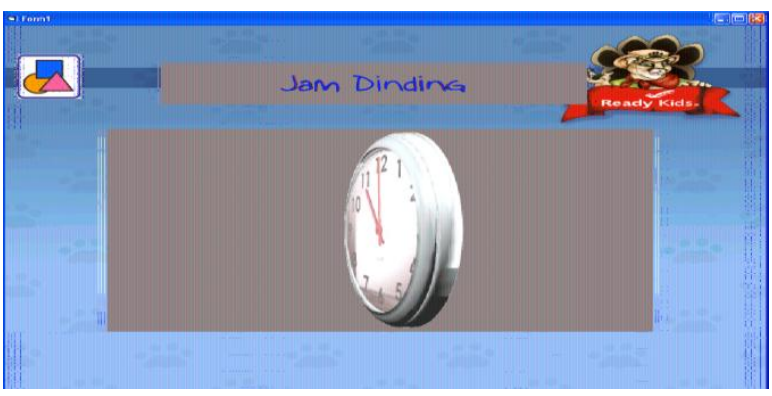

Gambar 4.3Tampilan form mengenal objek

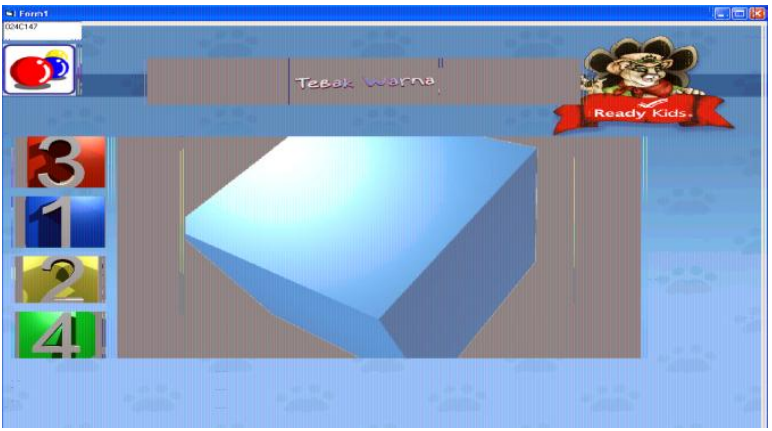

Gambar 4.4 Tampilan form menebak warna

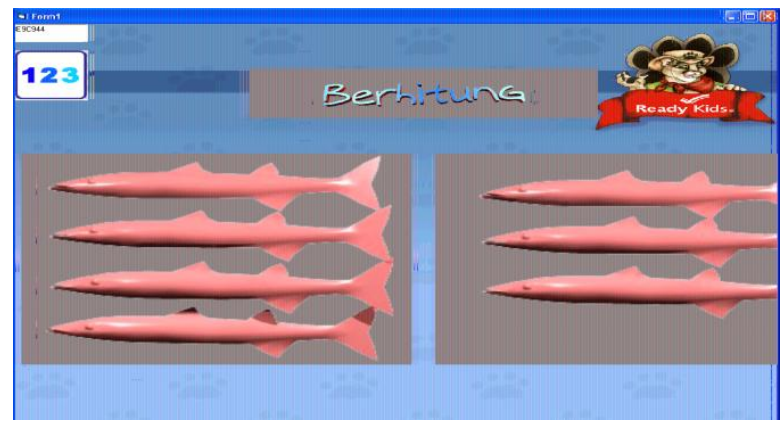

Gambar 4.5 Tampilan form belajar berhitung

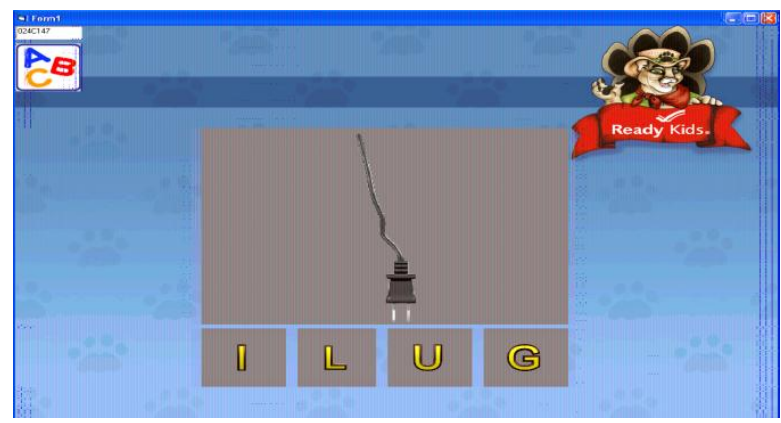

Gambar 4.6 Tampilan form belajar membaca

\subsection{HASIL PENGUJIAN DAN ANALISA} 4.2.1Hasil Pengujian dan Analisa Pembacaan RFID tag

Pada proses pengiriman dan penerimaan data dari RFID reader kepada PC digunakan kabel serial DB 9, hal ini bertujuan untuk mengetahui kondisi dari kabel data tersebut apakah baik atau tidak karena akan mempengaruhi keberhasilan dari akses tag RFID tersebut sebagai input untuk melakukan interaksi dalam proses belajar. Pengujian dilakukan dengan mengakses setiap tag RFID kepada reader RFID dan melakukan proses pengamatan dari data yang muncul pada Hyperterminal, dengan cara menghubungkan reader RFID ke port serial COM 1 pada komputer menggunakan kabel data, hasil pengujian dari proses pengiriman data yang ada pada RFID tag antara lain adalah, frekuensi yang di pancarkan oleh RFID reader yang akan dijadikan catu daya pada passive tag untuk proses backscattering pada sistem RFID, jarak pembacaan RFID reader terhadap tag, dan data RFID tag itu sendiri yang akan digunakan pada program aplikasi pembelajaran.

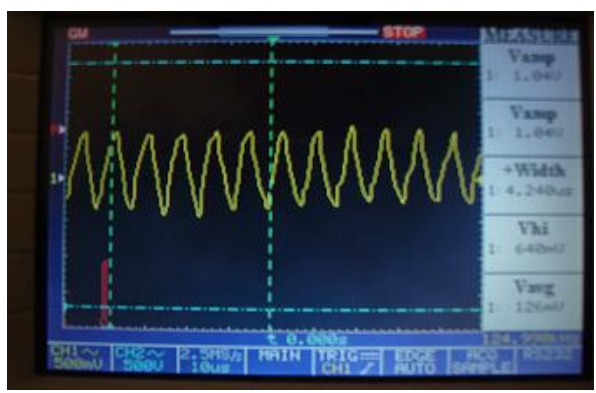

Gambar 4.7 Hasil pengukuran frekuensi RFID reader 
Dari hasil pengukuran dapat diamati nilai frekuensi yang dipancarkan pada RFID reader sebesar $125 \mathrm{Khz}$, yang berarti penggunaan tag RFID pada aplikasi ini menggunakan passive tag dimana pada passive tag jarak pembacaan antara RFID reader dan RFID tag harus dekat, karena untuk aplikasi pembelajaran yang interaktif, oleh karena itu dilakukan pengujian jarak pembacaan data RFID tag terhadap RFID reader.

Tabel 4.2 Hasil pengujian kondisi jarak kartu RFID tag pada pembaca

\begin{tabular}{|c|c|c|}
\hline $\begin{array}{c}\text { Jarak } \\
(\mathbf{c m})\end{array}$ & $\begin{array}{c}\text { Kondisi RFID tag } \\
\text { terhadap RFID } \\
\text { reader }\end{array}$ & $\begin{array}{c}\text { Kondisi } \\
\text { Buzzer }\end{array}$ \\
\hline $\mathbf{1 2}$ & Tidak terdeteksi & Tidak berbunyi \\
\hline $\mathbf{1 1}$ & Tidak terdeteksi & Tidak berbunyi \\
\hline $\mathbf{1 0}$ & Tidak terdeteksi & Tidak berbunyi \\
\hline $\mathbf{9}$ & Tidak terdeteksi & Tidak berbunyi \\
\hline $\mathbf{8}$ & Tidak terdeteksi & Tidak berbunyi \\
\hline $\mathbf{7}$ & Tidak terdeteksi & Tidak berbunyi \\
\hline $\mathbf{6}$ & Tidak terdeteksi & Tidak berbunyi \\
\hline $\mathbf{5}$ & Terdeteksi & berbunyi \\
\hline $\mathbf{4}$ & Terdeteksi & berbunyi \\
\hline $\mathbf{3}$ & Terdeteksi & berbunyi \\
\hline $\mathbf{2}$ & Terdeteksi & berbunyi \\
\hline $\mathbf{1}$ & Terdeteksi & berbunyi \\
\hline
\end{tabular}

Pengambilan data dari jarak pembacaan RFID reader terhadap tag dilakukan pada jarak $1 \mathrm{~cm}$ hingga $12 \mathrm{~cm}$, dari hasil pengujian pada tabel 4.2 dapat diamati bahwa jarak terjauh pembacaaan data RFID tag agar dapat terdeteksi oleh RFID reader adalah $5 \mathrm{~cm}$, sehingga untuk melakukan akses kartu RFID tag terhadap RFID reader pada penggunaan aplikasi pembelajaran ini harus dekat dan tidak boleh melebihi jarak $5 \mathrm{~cm}$.

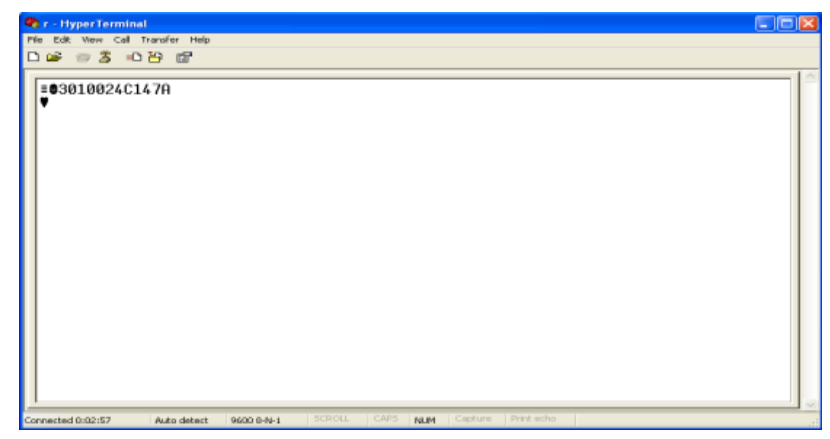

Gambar 4.8 Hasil pengujian kabel serial DB 9 pada kartu tag A

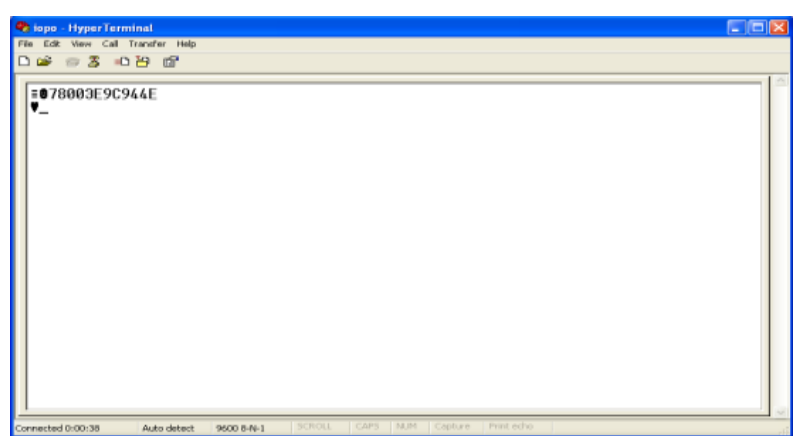

Gambar 4.10 Hasil pengujian kabel serial DB9 pada kartu tag B

Data yang diterima oleh hyperterminal merupakan data ID yang terdapat pada RFID tag yang akan digunakan pada program aplikasi pembelajaran pada saat kartu tersebut dideteksi reader RFID, hal ini terbukti bahwa kabel serial berfungsi dengan baik, pin yang digunakan pada kabel serial DB9 adalah pin 2,3, dan 5. pin 2 pada DB9 berfungsi sebagai sisi penerima dan pin 3 pada DB9 berfungsi sebagai sisi pengirim sedangkan pin 5 berfungsi sebagai sinyal ground, sehingga kabel data tersebut dapat mengirimkan data ID dari RFID tag ke PC.

\subsubsection{Hasil pengujian dan analisa program}

\subsubsection{Hasil pengujian setiap form aplikasi pembelajaran}

Tabel 4.3 Hasil pengujian form menu awal

\begin{tabular}{|c|c|c|c|c|c|c|c|}
\hline Filliki B & 0 & 1 & 2 & 3 & 4 & 5 & 6 \\
\hline 0 & & $\begin{array}{l}\text { Tidak ada pernhahan } \\
\text { tempilan }\end{array}$ & & & & & \\
\hline 1 & & $\begin{array}{l}\text { Option menu } \\
\text { mengenal obiek } \\
\text { ditympilling }\end{array}$ & 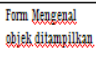 & & & & \\
\hline 2 & & & 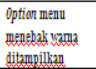 & $\begin{array}{l}\text { Fonn Yenethol } \\
\text { vema } \\
\text { ditampillkan }\end{array}$ & & & \\
\hline 3 & & & & $\begin{array}{l}\text { Option menu } \\
\text { belijax berituge } \\
\text { dittanpillkan }\end{array}$ & 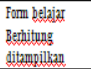 & & \\
\hline 4 & & & & & 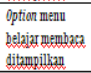 & $\begin{array}{l}\text { Fonm helpij } \\
\text { membera } \\
\text { ditampillyan }\end{array}$ & \\
\hline 5 & & & & & & 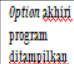 & 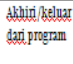 \\
\hline 6 & $\begin{array}{l}\text { Pengydangan } \\
\text { pemilithan } \\
\text { menu }\end{array}$ & & & & & & \\
\hline
\end{tabular}

Tabel 4.4 Hasil pengujian form mengenal objek

\begin{tabular}{|c|c|c|c|c|c|c|}
\hline Vilaili & 0 & 1 & 2 & 3 & 4 & 5 \\
\hline 0 & & $\begin{array}{l}\text { Menampilkan ojeded } \\
\text { jam dinding }\end{array}$ & $\begin{array}{l}\text { Yenzmpollkan obiek } \\
\text { kunci. }\end{array}$ & 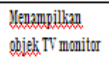 & $\begin{array}{l}\text { Yenguppilkan } \\
\text { chiek kursi }\end{array}$ & $\begin{array}{l}\text { Yengmpilkan } \\
\text { form menu } \\
\text { zyal }\end{array}$ \\
\hline 1 & 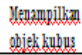 & & & & & \\
\hline 2 & $\begin{array}{l}\text { Yenempillkm } \\
\text { ebjek bola }\end{array}$ & & & & & \\
\hline 3 & $\begin{array}{l}\text { Yengmpilkng } \\
\text { ebiekprisma }\end{array}$ & & & & & \\
\hline 4 & 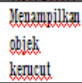 & & & & & \\
\hline 5 & $\begin{array}{l}\text { Yengmpilkn } \\
\text { obiek } \\
\text { silinder }\end{array}$ & & & & & \\
\hline
\end{tabular}


Tabel 4.5 Hasil pengujian form menebak warna

\begin{tabular}{|c|c|c|c|c|c|c|}
\hline $\int_{\text {vilai B }}^{\text {Nilai A }}$ & 0 & 1 & 2 & 3 & 4 & 5 \\
\hline 0 & & & & & & $\begin{array}{l}\text { Menampilkan } \\
\text { pertanyaan } \\
\text { ulang }\end{array}$ \\
\hline 1 & $\begin{array}{l}\text { Menampilkan } \\
\text { tekssalah } \\
\text { akseskartu }\end{array}$ & $\begin{array}{l}\text { Menampilkan } \\
\text { objek kubus } \\
\text { wama binu }\end{array}$ & & & & \\
\hline 2 & & $\begin{array}{l}\text { Menampilkan } \\
\text { teks anda } \\
\text { benar. }\end{array}$ & $\begin{array}{l}\text { Menampilkan } \\
\text { objekbola } \\
\text { wama kuning }\end{array}$ & & & \\
\hline 3 & & & $\begin{array}{l}\text { Menampilkan } \\
\text { teks anda belum } \\
\text { benar }\end{array}$ & & & \\
\hline 4 & & & $\begin{array}{l}\text { Menampilkan } \\
\text { teks anda benar }\end{array}$ & $\begin{array}{l}\text { Menampillkan } \\
\text { objek kerucut } \\
\text { wama merah }\end{array}$ & & \\
\hline 5 & & & & $\begin{array}{l}\text { Menampilkan } \\
\text { teks anda } \\
\text { belumbenar }\end{array}$ & & \\
\hline 6 & & & & $\begin{array}{l}\text { Menampilkan } \\
\text { teks anda } \\
\text { belumbenar }\end{array}$ & & \\
\hline 7 & & & & $\begin{array}{l}\text { Menampilkan } \\
\text { teks anda } \\
\text { benar }\end{array}$ & $\begin{array}{l}\text { Menampilkan } \\
\text { objek silinder } \\
\text { wama hijau }\end{array}$ & \\
\hline 8 & & & & & $\begin{array}{l}\text { Menampillkan } \\
\text { teks anda belum } \\
\text { benar }\end{array}$ & \\
\hline 9 & & & & & $\begin{array}{l}\text { Menampilikan } \\
\text { teks anda belum } \\
\text { benar }\end{array}$ & \\
\hline 10 & & & & & $\begin{array}{l}\text { Menampillkan } \\
\text { teks anda belum } \\
\text { benar }\end{array}$ & \\
\hline 11 & & & & & $\begin{array}{l}\text { Menampillkan } \\
\text { teks anda benar }\end{array}$ & \\
\hline 12 & & & & & $\begin{array}{l}\text { Menampilkan } \\
\text { form menu anyal }\end{array}$ & \\
\hline
\end{tabular}

Tabel 4.6 Hasil pengujian form belajar berhitung

\begin{tabular}{|c|c|c|c|c|c|c|}
\hline Silaila $\mathrm{A}$ & 0 & 1 & 2 & 3 & 4 & 5 \\
\hline 0 & & & & & & $\begin{array}{l}\text { Menampilkan } \\
\text { pertanyian } \\
\text { ulangi }\end{array}$ \\
\hline 1 & $\begin{array}{l}\text { Menampilkan } \\
\text { teks salah } \\
\text { akseskartu }\end{array}$ & $\begin{array}{l}\text { Menampilkan } \\
\text { ebjekk } 1 \text { ikan }\end{array}$ & & & & \\
\hline 2 & & $\begin{array}{l}\text { Menampilkan } \\
\text { sbjek satu } \\
\text { ikan dan teks } \\
\text { anda benar. }\end{array}$ & $\begin{array}{l}\text { Menampilkan } \\
\text { ebjek } 2 \text { ikan }\end{array}$ & & & \\
\hline 3 & & & $\begin{array}{l}\text { Menampilkan } \\
\text { skjek } 1 \text { ikan } \\
\text { danteks anda } \\
\text { belum benar }\end{array}$ & & & \\
\hline 4 & & & $\begin{array}{l}\text { Menampilkan } \\
\text { objek } 2 \text { ikan } \\
\text { dan teks anda } \\
\text { benar. }\end{array}$ & $\begin{array}{l}\text { Menampilkan } \\
\text { sbjek } 3 \text { ikan }\end{array}$ & & \\
\hline 5 & & & & $\begin{array}{l}\text { Menampilkan } \\
\text { sbiek } 1 \text { ikkan } \\
\text { danteks anda } \\
\text { belum benar. }\end{array}$ & & \\
\hline 6 & & & & $\begin{array}{l}\text { Menampilkan } \\
\text { sbiek } 2 \text { ikan } \\
\text { danteks anda } \\
\text { belum benar. }\end{array}$ & & \\
\hline 7 & & & & $\begin{array}{l}\text { Menampilkan } \\
\text { sbjek } 3 \text { ikan } \\
\text { danteks anda } \\
\text { belum benar }\end{array}$ & $\begin{array}{l}\text { Menampilkan } \\
\text { sbiek } 4 \text { ikan }\end{array}$ & \\
\hline 8 & & & & & $\begin{array}{l}\text { Menampiilkan } \\
\text { sbiek } 1 \text { kan dan } \\
\text { teks anda belum } \\
\text { benar. }\end{array}$ & \\
\hline 9 & & & & & $\begin{array}{l}\text { Menampilikan } \\
\text { sbiek } 2 \text { ikan dan } \\
\text { teks anda belum } \\
\text { benar. }\end{array}$ & \\
\hline
\end{tabular}

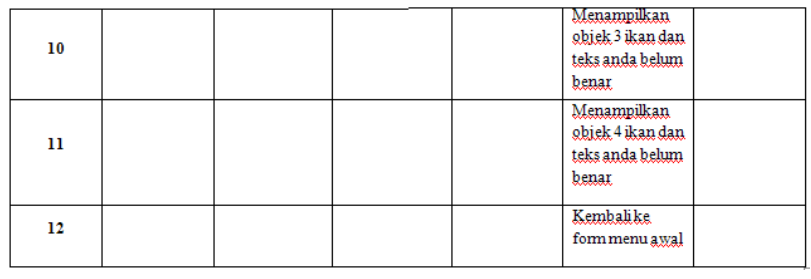

Tabel 4.7 Hasil pengujian form belajar membaca

\begin{tabular}{|c|c|c|c|c|c|c|}
\hline $\begin{array}{l}\text { Nilaht } \\
\text { Nilai B }\end{array}$ & 0 & 1 & 2 & 3 & 4 & 5 \\
\hline 0 & & & & & & $\begin{array}{l}\text { Menampilkan } \\
\text { pertanyaan } \\
\text { ulangi }\end{array}$ \\
\hline 1 & $\begin{array}{l}\text { Menampilkan } \\
\text { teks salah } \\
\text { akseskartu }\end{array}$ & $\begin{array}{l}\text { Menampillkan } \\
\text { objek angka } 1 \text {, } \\
\text { dan hunuf S, } \\
\text { A, U }\end{array}$ & & & & \\
\hline 2 & & $\begin{array}{l}\text { Menampillkan } \\
\text { teks anda } \\
\text { belumbenar }\end{array}$ & & & & \\
\hline 3 & & $\begin{array}{l}\text { Menampillkan } \\
\text { teks anda } \\
\text { belumbenar }\end{array}$ & & & & \\
\hline 4 & & $\begin{array}{l}\text { Menampillkan } \\
\text { huruf T dan } \\
\text { teks anda } \\
\text { benar. }\end{array}$ & $\begin{array}{l}\text { Menampillkan } \\
\text { sbiek bola dan } \\
\text { huruf } B, O, L\end{array}$ & & & \\
\hline 5 & & & $\begin{array}{l}\text { Menampilkan } \\
\text { teks anda } \\
\text { belum benar }\end{array}$ & & & \\
\hline 6 & & & $\begin{array}{l}\text { Menampillkan } \\
\text { teks anda } \\
\text { belum benar } \\
\end{array}$ & & & \\
\hline 7 & & & $\begin{array}{l}\text { Menampillkan } \\
\text { teks anda } \\
\text { belum benar }\end{array}$ & & & \\
\hline 8 & & & $\begin{array}{l}\text { Menampillkan } \\
\text { huruf A dan } \\
\text { teks anda } \\
\text { benar }\end{array}$ & $\begin{array}{l}\text { Menampilkan } \\
\text { objek ikan } \\
\text { dan huruf I, } \\
\text { A, N }\end{array}$ & & \\
\hline 9 & & & & $\begin{array}{l}\text { Menampilkan } \\
\text { teks anda } \\
\text { belum benar }\end{array}$ & & \\
\hline 10 & & & & $\begin{array}{l}\text { Menampilkan } \\
\text { hunuf } \mathrm{K} \text { dan } \\
\text { teks anda } \\
\text { benar }\end{array}$ & $\begin{array}{l}\text { Menampillkan } \\
\text { sbiek plug dan } \\
\text { huruf L, U, G }\end{array}$ & \\
\hline 11 & & & & & $\begin{array}{l}\text { Menampillkan } \\
\text { huruf P danteks } \\
\text { anda benar. }\end{array}$ & \\
\hline 12 & & & & & $\begin{array}{l}\text { Mengakhin } \\
\text { program }\end{array}$ & \\
\hline
\end{tabular}

\subsubsection{Analisa hasil pengujian pada program}

Dari hasil pengujian program yang ditunjukkan pada tabel 4.2, 4..3, 4.4, 4.5, dan 4.6, penggunaan dua kartu RFID tag dapat diterapkan pada suatu metode pembelajaran, hal ini dikarenakan adanya proses pemberian identifikasi dari data RFID tag pada program,

- Untuk data RFID tag “024C147” di identifikasi sebagai kartu A

- Untuk data RFID tag “3E9C944” di identifikasi sebagai kartu B

Setiap kartu RFID tag yang diakses dilakukan pemberian suatu nilai pada masing-masing kartu RFID tag, pada tabel hasil pengujian program dapat diamati ketika kartu A diakses satu kali, kartu A bernilai satu ketika kartu A diakses dua kali sehingga akan bernilai dua, begitu juga sama halnya yang terjadi pada kartu B,.

Nilai yang dihasilkan setiap kartu, tidak hanya dihasilkan dari pengaksesan setiap kartu yang 
bersangkutan, tetapi nilai tersebut dapat dihasilkan oleh kartu yang berbeda, contohnya pada form belajar berhitung, ketika kartu B terlebih dahulu diakses, kartu B akan bernilai satu, tampilan yang dihasilkan adalah suatu pesan yang berisi salah akses kartu, selanjutnya program akan menganggap kartu B bernilai nol/tidak ada akses sama sekali dari kartu B, hal ini bertujuan untuk penggunaan kartu A harus terlebih dahulu diakses pada form ini, ketika kartu A sudah diakses, kartu A akan bernilai satu serta B juga akan bernilai satu meskipun kartu B belum diakses ataupun sudah diakses, hal ini bertujuan agar pengaksesan kartu B yang berikutnya akan bernilai dua bukan bernilai satu, dibawah ini merupakan kutipan kode program yang membahas dari analisa yang disebutkan sebelumnya tentang pemberian nilai pada karu A dan B.

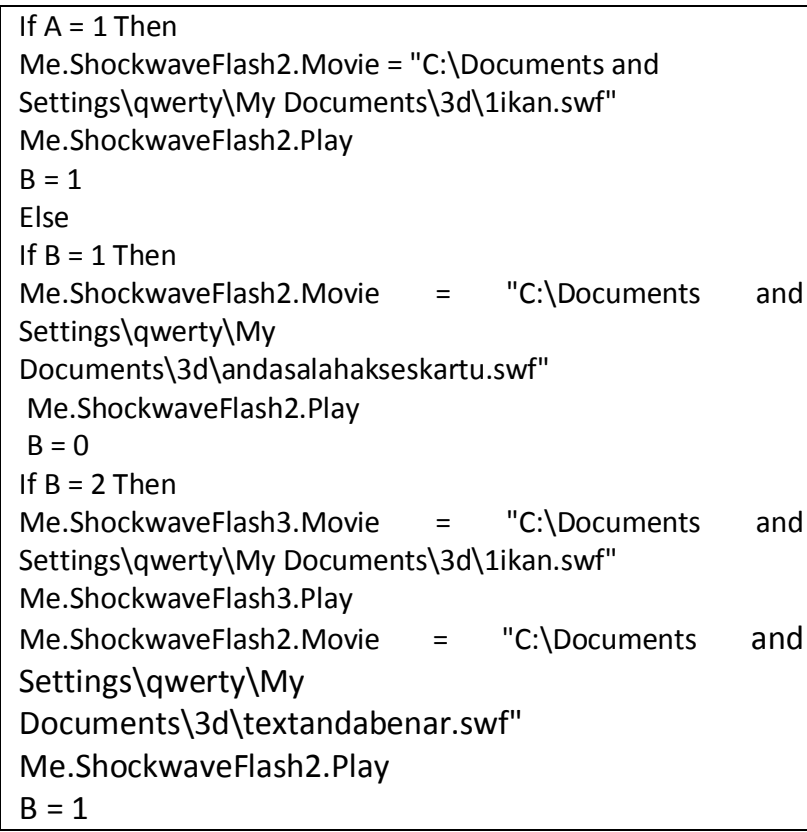

Tujuan dari keharusan kartu A yang terlebih dahulu diakses adalah seperti yang sudah dijelaskan pada sub bab 4.1.2 bahwa fungsi dari kartu $\mathrm{A}$ adalah untuk menampilkan soal pembelajaran, sedangkan pada proses belajar tidak diperbolehkan untuk menampilkan jawaban terlebih dahulu, sehingga ini yang menjadi suatu alasan dari penggunaan kartu A terlebih dahulu yang diakses, selain kartu A yang dapat memberikan suatu nilai terhadap kartu B, kartu B juga dapat memberikan dua kondisi nilai terhadap kartu B itu sendiri, hal ini dapat ditunjukkan pada kutipan program diatas, ketika kartu B bernilai dua selanjutnya program akan menampilkan pesan teks anda benar, dan men-set kartu B bernilai satu, hal ini bertujuan untuk pengaksesan kartu B selanjutnya tidak bernilai tiga tetapi bernilai satu dan melakukan proses pengulangan antara nilai satu dan dua, karena nilai tiga pada kartu B digunakan untuk menjawab soal selanjutnya.

Nilai yang dihasilkan dari kartu A dan B, berasal dari persamaan dibawah ini yang ada pada program:

- $\mathrm{A}=\mathrm{A}+1$.
- $\quad \mathrm{B}=\mathrm{B}+1$

Akan menghasilkan nilai satu jika diakses satu kali, menghasilkan nilai dua jika diakses dua kali dan seterusnya dari setiap penggunaan kartu A dan B yang diakses. Dengan pemberian nilai terhadap kartu A dan B dari persamaan yang disebutkan diatas sehingga setiap kartu RFID tag dapat mengidentifikasikan berbagai macam objek yang ingin ditampilkan pada proses pembelajaran.

\section{KESIMPULAN}

Dari hasil pengujian dan analisa pada bab sebelumnya maka dapat diambil kesimpulan

- RFID tag dapat mengidentifikasikan bermacammacam objek dengan pemberian identifikasi pada masing-masing data tag menjadi A dan B pada program, dan mengikuti persamaan $\mathrm{A}=\mathrm{A}+1$ untuk kartu $\mathrm{A}$, dan $\mathrm{B}=\mathrm{B}+1$ untuk kartu $\mathrm{B}$, sehingga pada aplikasi pembelajaran ini hanya digunakan sepasang RFID tag.

- Digunakan dua RFID tag yang bertujuan mengelompokkan perintah untuk menjalankan aplikasi pembelajaran, kartu A berfungsi untuk menampilkan objek dan soal, sedangkan untuk kartu B berfungsi untuk menjawab pertanyaan yang ditampilkan oleh kartu A serta menampilkan objek dan mengakhiri program.

- Interface antara RFID reader dengan pemrograman Ms. Visual basic adalah pada penggunaan komponen MSComm yang berfungsi untuk melewat kan data pada serial port

\section{DAFTAR PUSTAKA}

[1] Diki, Muhammad, "Aplikasi Akses Pintu Menggunakan RFID berbasis DATABASE, Teknik Telekomunikasi”, PoliteknikNegeri Jakarta, 2007.

[2] Finkenzeller, Klaus, "Fundamentals and Applications in Contactless Smart Cards and Identification 2nd Edition", John Wiley and Sons Ltd, 2003.

[3]

http://www.adilam.com.au/RFID/Adilam\%20 RFID\%20ID12.pdf

[4] http://www.ari-sty.cz.cc/2009/11/antarmuka-ieddengan-pc-melalui-mscomm.html

[5] http://www.enigmaticconsulting.com/Communications_articles/RFID/L ink_budgets.html

[6] http://www.ristishop.com/index.php?ch= 8\&lang=ind\&s=7d6bc9c0ff2fbe2f8824098a3ef4b $3 \mathrm{~d} 6 \& n=369$ 
